\title{
Drugging the undruggables: exploring the ubiquitin system for drug development
}

\author{
Xiaodong Huang ${ }^{1}$, Vishva M Dixit ${ }^{2}$ \\ ${ }^{1}$ Department of Discovery Oncology, Genentech, Inc., 1 DNA Way, South San Francisco, CA 94080, USA; ${ }^{2}$ Department of Physio- \\ logical Chemistry, Genentech, Inc., 1 DNA Way, South San Francisco, CA 94080, USA
}

Dynamic modulation of protein levels is tightly controlled in response to physiological cues. In mammalian cells, much of the protein degradation is carried out by the ubiquitin-proteasome system (UPS). Similar to kinases, components of the ubiquitin system are often dysregulated, leading to a variety of diseases, including cancer and neurodegeneration, making them attractive drug targets. However, so far there are only a handful of drugs targeting the ubiquitin system that have been approved by the FDA. Here, we review possible therapeutic intervention nodes in the ubiquitin system, analyze the challenges, and highlight the most promising strategies to target the UPS.

Keywords: ubiquitin-proteasome system; drug target; degrader; PROTAC; hydrophobic tag; SERD

Cell Research (2016) 26:484-498. doi:10.1038/cr.2016.31; published online 22 March 2016

\section{Introduction}

Ubiquitination is a post-translational modification, where a small protein, ubiquitin, is covalently attached to lysine residues on a substrate protein [1]. This modification is carried out sequentially by a cascade of enzymatic reactions involving an intimate collaboration between E1 activating, E2 conjugating and E3 ligating enzymes. Ubiquitin is first activated by $\mathrm{E} 1$ and enters into a thioester linkage with the catalytic cysteine; it is then transferred through a trans-esterification reaction to an E2 conjugating enzyme. Subsequently, E3 ligases either behave as bona fide enzymes (HECT E3s), or a "matchmaker" (RING E3s), to transfer ubiquitin from a charged E2 to substrates, facilitating the formation of an isopeptide bond between the $\mathrm{C}$ terminal glycine of ubiquitin and substrate lysine residue [1] (Figure 1).

Since ubiquitin itself has seven lysine residues, this modification can be dispersed and propagated, by transferring additional ubiquitin molecules to one of the seven lysine residues or the $\mathrm{N}$-terminal amino group, to form eight homogeneous or multiple mixed or branched chain types [1]. Depending on the chain topology, ubiquitina-

Correspondence: Xiaodong Huang ${ }^{\mathrm{a}}$, Vishva Dixit ${ }^{\mathrm{b}}$

${ }^{a}$ E-mail: huang.xiaodong@gene.com

${ }^{\mathrm{b}}$ E-mail: dixit@gene.com tion can lead to different biological outcomes. For example, K48 and K11 chains are related to degradation by the proteasome [2-4], whereas K63 and linear ubiquitin chains have a scaffolding role for signaling assemblies and play a prominent role in many biological processes, including inflammation $[3,5]$.

Like other post-translational modifications, ubiquitination is reversible and countered by $\sim 100$ deubiquitinases (DUBs) encoded in the human genome $[6,7]$. DUBs are proteases composed of five sub-families, including ubiquitin carboxyl-terminal hydrolases (UCH), ubiquitin specific proteases (USP), ovarian tumor like proteases (OTU), JAMM/MPN metalloproteases and Machado-Jacob-disease proteases (MJD). All DUBs are cysteine proteases other than the JAMM/MPN metalloproteases [6].

Since ubiquitination regulates a variety of complex cellular processes ranging from protein degradation to modulating protein-protein interactions, from endocytosis to cell cycle progression, from activating to inactivating substrates, it is not surprising that one or more components in the system could go awry, leading to a variety of diseases, including cancer and neurodegeneration [8]. For example, mutations in PARKIN, an E3 ligase, are known to cause a familial form of Parkinson's disease [9]; and chromosomal translocation of USP6 gene is linked to aneurysmal bone cyst, a local aggressive osseous lesion [10].

The success of the kinase inhibitors in the last two 


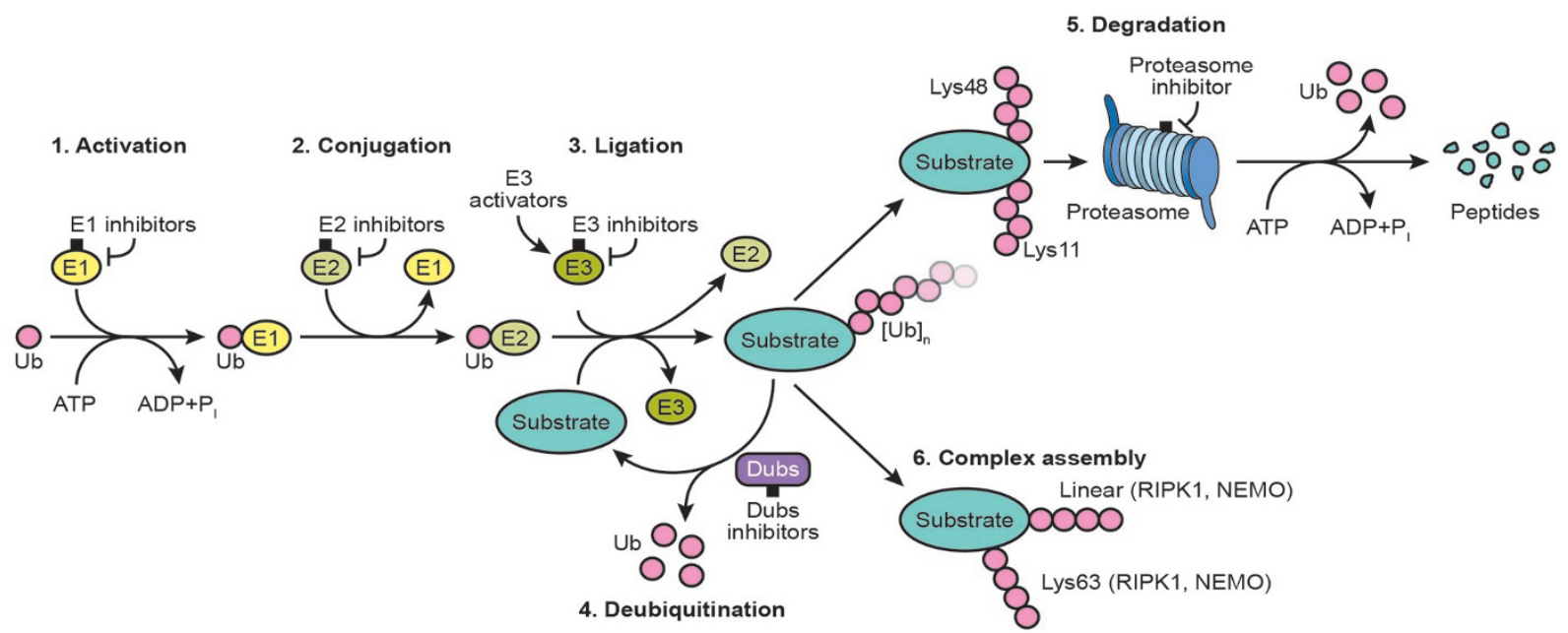

Figure 1 Summary of the ubiquitin system and possible intervention nodes. Ubiquitination is an ATP-dependent process carried out by three classes of enzymes. E1 activating enzymes form a thioester bond with ubiquitin, followed by subsequent binding of ubiquitin to E2 conjugating enzymes, and ultimately the formation of an isopeptide bond between the carboxyl-terminal glycine of ubiquitin and a lysine residue on the substrate protein, which requires E3 ubiquitin ligases. Multiple intervention nodes in the reaction cascade have been proposed to either block or enhance ubiquitination.

decades has prompted the pharmaceutical industry to attempt the same strategy in targeting the ubiquitin system $[11,12]$. However, progress has been slow. So far, only a handful of small molecules have been successfully developed. This is largely because most components of the ubiquitin system do not carry out a readily identifiable enzymatic function with a well-defined catalytic pocket, making them difficult small molecule targets; secondly, ubiquitination depends on the dynamic rearrangement of multiple protein-protein interactions that traditionally have been challenging to disrupt with small molecules.

In spite of this complexity, with advances in technology and better understanding of ubiquitination biology, industry remains committed to drug development in this area. Below we will review the involvement of ubiquitination system in human diseases and the progress that has been made to target the ubiquitin system. In addition to inhibitors, we also discuss advances in activating ubiquitination to degrade the most difficult targets.

\section{Targeting E1 activating enzymes}

Ubiquitin activating enzymes (UBEs or E1 enzymes) are at the apex of the ubiquitination cascade. As an ATPdependent step, E1 enzymes catalyze the formation of a thioester bond between the C-terminal carboxyl group of ubiquitin and the cysteine residue of E1 itself [13]. To date, there are two ubiquitin E1 enzymes identified in humans, UBA1 and UBA6, which control ubiquitination of all downstream targets [14].
PYR-41 was the first identified cell permeable inhibitor for UBA1 [15]. The structure of PYR-41 suggests it is an irreversible inhibitor since it is subject to nucleophilic attack and potentially could covalently modify the active cysteine $\left(\mathrm{Cys}^{632}\right)$ of UBA1 [15]. Similar to PYR41, PYZD-4409 is another UBE1 inhibitor based on a pyrazolidine pharmacophore [16]. Although both PYR41 and PYZD-4409 preferentially induce cell death in malignant cell lines and primary patient samples, the precise mechanism of action of these compounds and off-target activities are currently incompletely characterized.

In addition to ubiquitin, there are more than a dozen ubiquitin-like molecules (Ubls) in mammals that are all activated by an equivalent enzymatic cascade for conjugation to their cognate substrates [17]. One of these Ubl-conjugation pathways involves NEDD8, an Ubl molecule that shares $\sim 60 \%$ sequence similarity with ubiquitin. Like ubiquitination, neddylated substrates, in particular cullins - the regulatory scaffold of multi-subunit E3-ligases - play a critical role in cell proliferation. Therefore, a NEDD8 activating enzyme (NAE) inhibitor was expected to possess anti-cancer therapeutic potential. The most promising NAE inhibitor, MLN4924, is currently being evaluated in several phase II studies with promising preliminary results [18]. MLN4924 induces cell death due to uncontrolled DNA synthesis during S-phase of the cell cycle, leading to DNA damage and induction of apoptosis, suggesting that proliferating tumor cells are more susceptible to NAE inhibition [18]. 
MLN4924 interacts with the nucleotide-binding site within NAE and forms a covalent adduct that mimics NEDD8-AMP, but cannot participate in subsequent reactions, resulting in the blockage of NAE function [19].

Among all neddylated proteins, cullin family members, the core scaffolds of SCF (SKP, Cullin, F-box) E3 ligases, are best characterized. Neddylation of cullin changes the conformation of the cullin $\mathrm{C}$-terminal domain and enables ubiquitin transfer [20]. Indeed, MLN4924 treatment disrupted CRL (Cullin RING ligase) -mediated protein turnover, resulting in the accumulation of both oncoproteins as well as tumor suppressors such as NRF2, p27, and I $\kappa$ B [21-23]. Therefore, the mechanisms of action of MLN4924 is intimately linked to the attenuation of a multitude of cullin RING E3 ligases.

Although many E1 inhibitors have been developed, except for MLN4924, none has entered clinical trials, most likely due to issues of specificity or poor druglike properties. Importantly, E1 inhibitors should not be considered equivalent to proteasome inhibitors, which induce accumulation of ubiquitinated substrates.

\section{Targeting E2 conjugating enzymes}

The E2 ubiquitin conjugating enzymes interact with numerous downstream E3 ligases to transfer charged ubiquitin molecules that are in labile thioester linkage onto substrate proteins [24]. Traditionally, E2 enzymes were treated as "ubiquitin carriers", but recent work suggests that these enzymes not only dictate ubiquitin chain linkage and length of chain, but in many cases also determine substrate specificity [17]. Furthermore, there are $\sim 38$ E2 enzymes in mammals, making it a class of targets with potentially more specificity than E1 enzymes [24]. Given this, targeting E2 enzymes should provide more selectivity than E1 enzymes.

A compound CC0651, identified to potently inhibit the ubiquitination of $\mathrm{p} 27^{\mathrm{KIP} 1}$ by the $\mathrm{E} 3$ ligase $\mathrm{SCF}^{\mathrm{SKP} 2}$ was instead discovered to be an allosteric inhibitor of an E2 enzyme, CDC34 [25]. Mechanistically, CC0651 inserts into a cryptic binding pocket in $\mathrm{CDC} 34$ distant from the catalytic site, causing conformational rearrangement that interferes with the discharge of charged ubiquitin to acceptor lysine residues. Despite promising data in vitro, however, further development of CC0651 has largely failed due to difficulties in optimization (http://www. nature.com/scibx/journal/v4/n28/full/scibx.2011.784.ht$\mathrm{ml} \# \mathrm{~B} 1$ ).

The UBE2N-UBE2V1 heterodimer is an E2 enzyme that catalyzes the synthesis of $\mathrm{K} 63$-specific poly-ubiquitin chains. UBE2N is the active subunit, whereas UBE2V1 is an E2 variant that lacks the active site cys- teine residue [26]. NSC697923 is a small molecule that inhibits the formation of UBE2N Ub thioester conjugates, thereby blocking transfer of ubiquitin to substrates [27]. Another UBE2N inhibitor BAY 11-7082 was first thought to inhibit IKK since it blocked IKB- $\alpha$ phosphorylation in cells [28], but a recent study suggests that BAY 11-7082 actually exerts these effects by covalently modifying the reactive cysteine residues of UBE2N and possibly several other E2 enzymes [29].

\section{Targeting E3 ligases}

The ubiquitin E3 ligase family is the largest family in ubiquitin signaling with $\sim 700$ members identified or predicted to possess ligase activities [30]. There are three subfamilies of E3 ubiquitin ligases: RING E3s, which act as scaffolding molecules to bring ubiquitin-charged E2 enzymes in close contact with their substrates; HECT E3s, which catalyze the transfer of ubiquitin to their own cysteine residues and subsequently to substrates, and a third subfamily, RING-Between-RING (RBR) E3s, which include PARKIN and ARIH1, and mechanistically behave as hybrids between RING and HECT [31-33]. As E3s are a large family of enzymes that use distinct catalytic mechanisms, targeting E3s is anticipated to yield better specificity, less toxicity and be a more superior option. It is impossible to cover all efforts to target E3 ligases; instead we will focus on several most promising examples listed below.

\section{$S C F^{S K P 2}$}

The F-box protein SKP2 forms a complex with CUL1, SKP1, and a RING finger protein RBX1, together termed $\mathrm{SCF}^{\text {SKP2 }}$ [34]. SKP2 was first identified as a critical cell cycle regulator because it ubiquitinates several important cell cycle regulators, including $\mathrm{p} 27^{\mathrm{KIP} 1}$ and $\mathrm{p} 21^{\mathrm{CIP} 1}$, both are critical CDK inhibitors [35-37]. SKP2 also plays a critical role in EGFR-mediated AKT ubiquitination and membrane recruitment [38]. The oncogenic potential of SKP2 was suggested by its overexpression in a variety of human cancers $[39,40]$. Importantly, this overexpression of SKP2 showed an inverse relationship with p $27^{\mathrm{KIP} 1}[41$, 42]. Furthermore, the protein levels of SKP2 could serve as a prognostic biomarker, with higher levels predicting poor patient survival $[38,41,43]$.

Given the importance of SKP2 in regulating degradation of tumor suppressors and its clear oncogenic potential, inhibiting SKP2 may represent a unique opportunity for the treatment of different types of tumors. Unfortunately, unlike kinases, $\mathrm{SCF}^{\mathrm{SKP} 2}$ is a large multi-subunit complex, and does not possess any obvious cavity for targeting by small molecules. However, the success of 
developing GDC-199 (venetoclax), an inhibitor for a protein that does not have enzymatic activity (BCL2) has convinced many that the time for disrupting protein-protein interactions might finally be here [44]. Indeed SKP2 does have several potential protein interaction interfaces that could be explored by small molecules to disrupt interaction with either p27 or SKP1 (Figure 2A).

Pocket 3, for example, is formed jointly by SKP2 and CKS1, which is essential for $\mathrm{p} 27$ binding and ubiquitination by SKP2 (Figure 2A). The pocket was interrogated in a virtual screen and 96 hits were confirmed in biochemical and biophysical studies [45]. These compounds selectively inhibit SKP2-p2 $7^{\mathrm{KIP} 1}$ interaction, and therefore block the degradation of $\mathrm{p} 27^{\mathrm{KIP} 1}$.

In another in silico screening effort, compound 25 was identified to selectively suppress $\mathrm{SCF}^{\mathrm{SK} 2}$, but not other SCF E3 ligase activities [46]. Mechanistically, compound 25 disrupts the interaction between SKP1-SKP2 and thus abrogates $\mathrm{SCF}^{\mathrm{SKP} 2}$ ligase activity. Although no crystal structure is available, compound 25 presumably occupies pocket 1 , but not pocket 2 of SKP2, both of which are critical for SKP1-SKP2 interaction (Figure 2A). However, careful analysis of pocket 1 and compound 25 suggests that the ligand might not fully occupy the pocket. Interestingly, the available structure of SKP2 lacks the N-terminal 96 amino acids [47]. A potential explanation is that the missing $\mathrm{N}$-terminal segment could fold back to buttress compound 25 to ensure a snug fit in the pocket. Despite this caveat, compound 25 exhibits potent antitumor activities in multiple animal models and synergistically inhibits tumor survival with chemotherapeutic agents (Figure 2B) [46], confirming that inhibiting $\mathrm{SCF}^{\mathrm{SKP} 2}$ is potentially beneficial for cancer patients.

\section{MDM2}

As the guardian of the genome, p53 is arguably one of the most important tumor suppressors that controls the regulation and expression of many genes that mediate cell cycle arrest, DNA repair and apoptosis [48]. Under physiological conditions, newly synthesized p53 quickly undergoes ubiquitination and degradation, resulting in a "futile cycle" and a very low "steady-state" level of protein. This is largely controlled by a RING finger E3 ligase, MDM2 (murine double minute 2, HDM2 in human) [49]. In addition to being a transcriptional inhibitor of $\mathrm{p} 53$, MDM2 also tightly interacts with $\mathrm{p} 53$ protein itself by recognizing the N-terminal transactivation domain (TAD), allowing p53 to undergo ubiquitination and subsequent proteasomal degradation [50,51]. As a negative regulator of $\mathrm{p} 53, M D M 2$ is overexpressed in many cancers by either gene amplification or transcriptional up-regulation [52]. Furthermore, overexpression
A

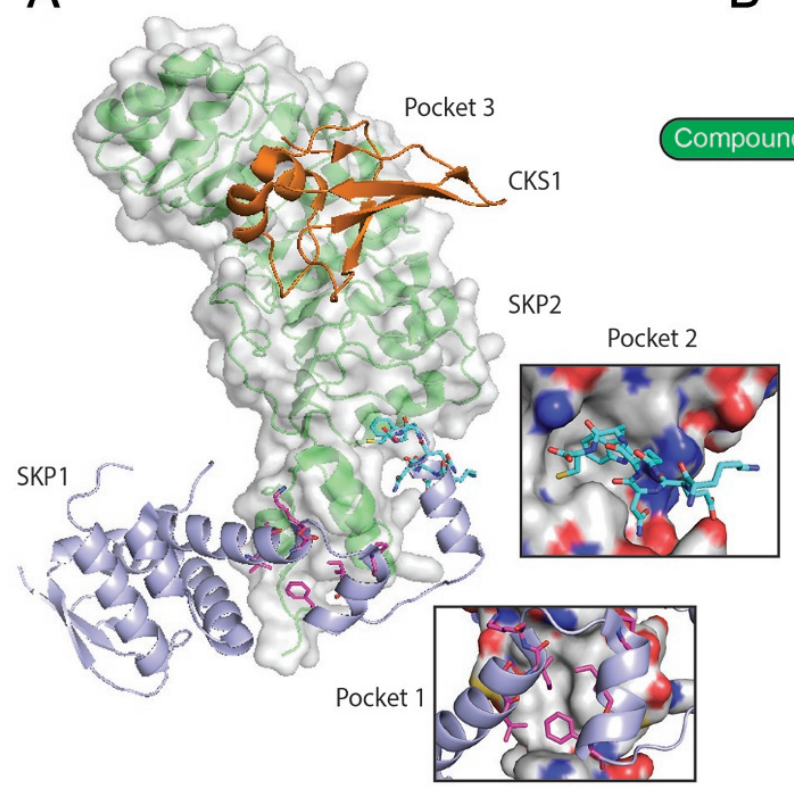

B

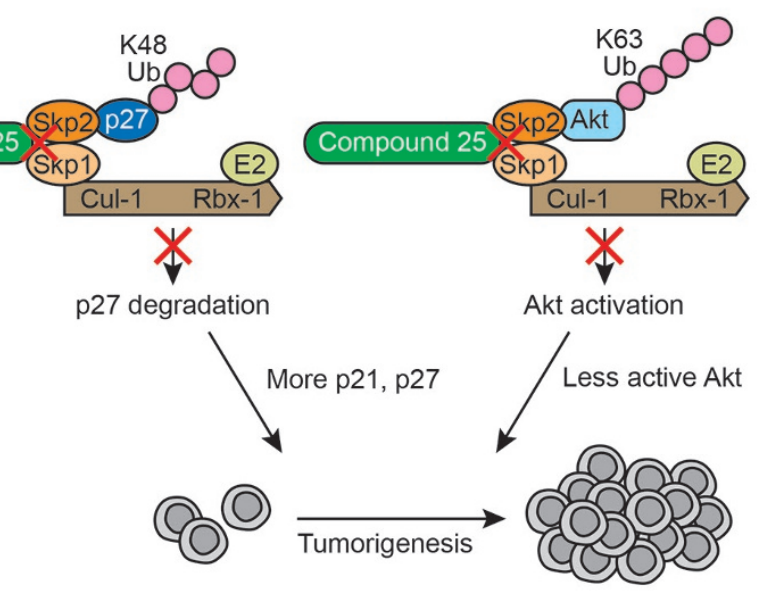

Figure $2 \mathrm{SCF}^{\mathrm{SKP} 2}$ as a possible anti-cancer target. (A) The crystal structure of SCF ${ }^{\mathrm{SKP} 2}$ highlights potential interfaces (pockets 1-3) that small molecule inhibitors can bind to and block its E3 ligase function. (B) Compound 25 has been identified to be a selective $\mathrm{SCF}^{\mathrm{SKP} 2}$ inhibitor. It blocks ubiquitination and degradation of p27, as well as ubiquitination and activation of AKT. Together, this compound exhibits potent antitumor activities in multiple animal models. 
of MDM2 has been linked to worse prognosis in different types of tumors, correlating with altered p53 protein levels, although it has not been confirmed whether these tumors have wild-type or mutant p53 [53, 54].

Its oncogenic potential as well as being a negative regulator of p53 warrants consideration of MDM2 as an attractive drug target. Among all the small molecules that inhibit MDM2, Nutlins, a family of cis-imidazoline analogues identified by high-throughput screening, holds the greatest potential and is currently being tested in clinical trials (Figure 3). Importantly, Nutlin treatment showed a dose-dependent anti-proliferative and cytotoxic activity that differed between cell lines depending on their p53 status [55]. Furthermore, as anticipated, Nutlin treatment induced accumulation of wild-type, but not mutant p53 protein.

In addition to Nutlins, a couple of other small molecules have also been identified to disrupt MDM2-p53 interaction. For example, similar to Nutlins, MI-219 binds MDM2 and blocks its interaction with $\mathrm{p} 53$, leading to induction of cell cycle arrest and selective apoptosis in tumor cells [56]. Another promising molecule, RITA (reactivation of $\mathrm{p} 53$ and induction of tumor cell apoptosis) has been shown to prevent the interaction of p53 and MDM2 and to induce p53 accumulation in tumor cells [57]. In contrast to Nutlins, RITA binds p53 but not MDM2; therefore it might inhibit many other interactions of $\mathrm{p} 53$ that have little to do with ubiquitination of $\mathrm{p} 53$.

Although the small molecules disrupting MDM2-p53 interaction hold great potential in restoring p53 function, one caveat is that they are only efficacious in tumors harboring wild-type p53, as most p53 mutants are no longer subject to ubiquitination by MDM2 and become stabilized [58]. Instead, molecules aiming to restore the native conformation of p53 mutants and reactivate their tumor-suppressor function may be of more benefit to a broader spectrum of cancers. For instance: PRIMA-1 and its analog APR-246 covalently modify p53 mutants through the alkylation of thiol groups, restoring wildtype conformation and function to mutant p53 [59].

\section{Inhibitor of apoptosis proteins}

Inhibitors of apoptosis proteins (IAPs) are a family of anti-apoptosis proteins that function in part by inhibiting caspases. In humans, there are at least eight IAP family members [60]. All IAP proteins have one to three baculoviral IAP repeat (BIR) domains that participate in binding caspases [60]. Most IAPs have a RING domain at their C-terminus that is required for ubiquitination of their substrates as well as auto-ubiquitination of some members including c-IAP1, c-IAP2 and X-linked inhibitor of apoptosis (XIAP) [61, 62]. IAP proteins are implicated in various cancers and attempts are being made to target them using small molecule inhibitors or antisense oligonucleotides [63].

SMAC/DIABLO is a mitochondrial protein that is released to bind and inhibit IAPs during apoptosis, thereby freeing caspases to activate apoptosis $[64,65]$. Initial effort to generate IAP antagonists was aimed at mimicking the four amino-terminal residues of mature active SMAC

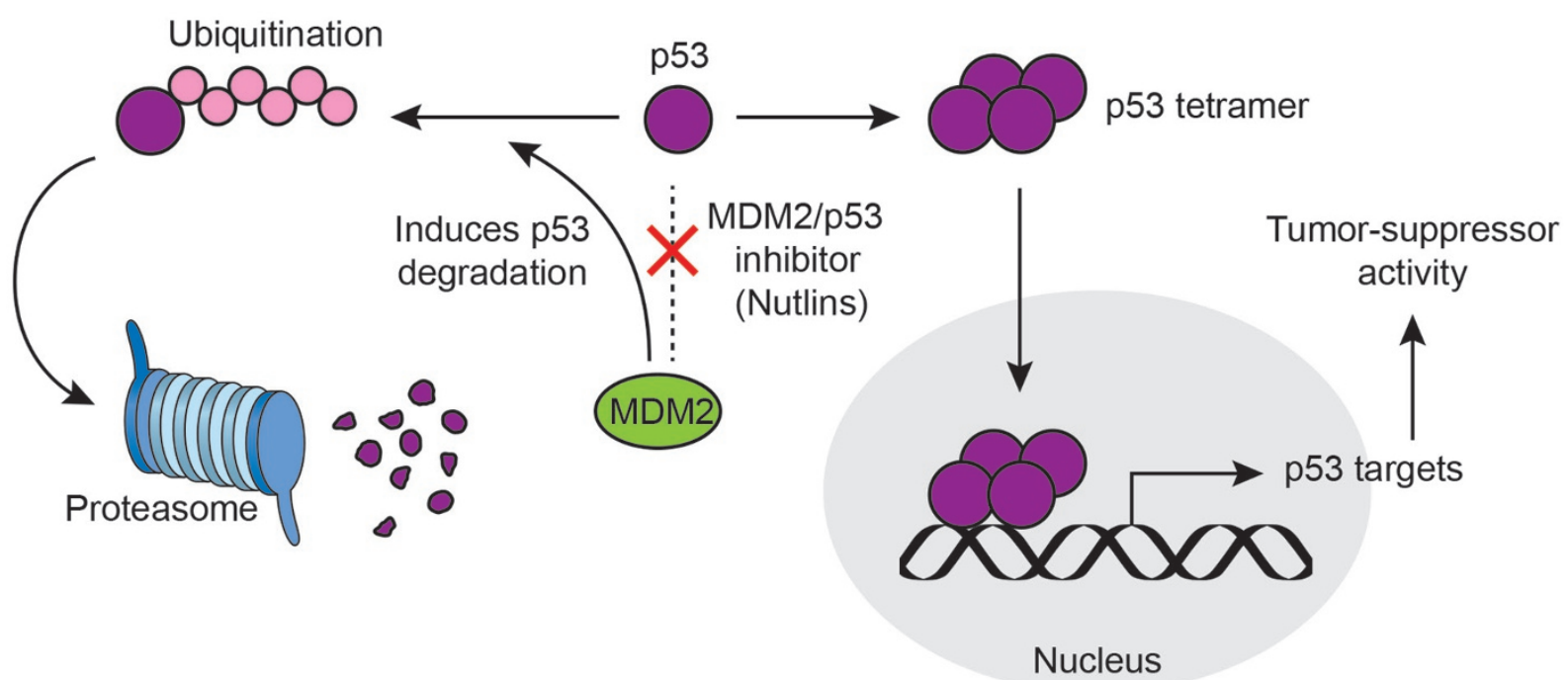

Figure 3 MDM2 as a potential anti-cancer target. p53 is rapidly ubiquitinated by MDM2 and degraded via the proteasome. Nutlins (and other MDM2/p53 interaction inhibitors) disrupt the interaction between MDM2 and p53, resulting in accumulation of p53 and its anti-tumor effect. 
that binds IAP. Several monovalent IAP antagonists containing a single SMAC AVPI-like motif were shown to effectively bind the BIR domains of IAP and induce apoptosis in cancer cells [66]. Further optimized bivalent antagonists consist of two SMAC-mimetic motifs connected by a chemical linker, allowing simultaneous binding to the BIR2 and BIR3 domains of IAPs, leading to an even more robust activation of caspases and apoptosis [66]. Interestingly, IAP antagonists induce a conformational change and formation of IAP dimers, leading to robust auto-ligase activity, auto-ubiquitination and ultimately degradation [67], consistent with IAP inhibitors behaving as "suicidal degraders". Currently, a couple of IAP antagonists are under investigation in several phase I trials [63].

\section{Targeting the proteasome}

Proteasome inhibitors were originally developed to treat cachexia, which occurs in patients with advanced cancers and is characterized by a catabolic state that leads to progressive wasting [68]. Although the mechanism of cachexia was not completely clear at the time, it was postulated that a proteasome inhibitor would be effective to prevent protein degradation and muscle wasting [69]. The best-known proteasome inhibitor, MG132, a peptide aldehyde that is widely used in research, emerged from early work to develop a proteasome inhibitor. Although never tested clinically due to rapid oxidation, it proved to be a valuable research tool [70]. Currently, there are two proteasome inhibitors approved by FDA, bortezomib (Velcade), a peptide boronate, and carfilzomib (Kyprolis), a peptide epoxyketone.

Bortezomib (PS341, Velcade) was the first proteasome inhibitor to enter clinical trials. As a peptide boronate, it reversibly forms tetrahedral adducts with $\mathrm{Thr}^{1}$ residues in the catalytic $\beta 5$ subunits with an extremely low dissociation rate, explaining its extraordinary potency: $\mathrm{EC}_{50}$ of $0.6 \mathrm{nM}$ for proteasome's chymotryptic activity. In phase I trials, bortezomib initially showed only unremarkable activity in solid cancer patients. Subsequently, however, it was found to induce dramatic disease regression in multiple myeloma patients [71]. The mechanism of efficacy is not completely clear, but it is generally accepted that treatment with bortezomib results in stabilization of $\mathrm{I}-\kappa \mathrm{B}$, an important suppressor of NF- $\mathrm{BB}$ signaling [72]. In addition, bortezomib also causes accumulation of two important negative regulators of the cell cycle, $\mathrm{p} 27^{\mathrm{KIP} 1}$ and $\mathrm{p} 53$, both of which are important tumor suppressors [73]. Another potential benefit of bortezomib treatment might be the accumulation of the pro-apoptotic protein BAX, thereby shifting the balance towards apoptosis [74].
Last, but not least, bortezomib also induces endoplasmic reticulum stress and oxidative stress in cancer cells that may precipitate apoptosis [75].

Carfilzomib (PR-171, Kyprolis), a tetrapeptide epoxyketone, is the second proteasome inhibitor approved by the FDA [76]. Derived from epoxomicin, the $\alpha$, $\beta$-epoxyketone moiety of carfilzomib binds to both the hydroxyl group and the free $\alpha$-amino group of $\mathrm{Thr}^{1}$ in the catalytic $\beta 5$ subunits, forming a morpholino adduct and blocking access of substrate proteins to the catalytic residues [77-79]. Since non-proteasomal serine and cysteine proteases do not have the free $\alpha$-amino group required for adduct formation with carfilzomib, these proteases are not affected, explaining its high specificity. Carfilzomib irreversibly inhibits proteasomal activity to less than $20 \%$, therefore the only way to restore proteasome activity is through newly synthesized and assembled proteasomes. Hence, carfilzomib is more potent than bortezomib, inducing responses in bortezomib-resistant multiple myeloma [76].

Although bortezomib and carfilzomib show excellent efficacy in multiple myeloma, both have to be administered systemically, therefore improving oral bioavailability will be a major goal in the development of next generation proteasome inhibitors [80]. To this end, MLN9708 (ixazomib citrate) was developed as an orally bioavailable second-generation proteasome inhibitor. Similar to the first generation, MLN9708 triggered apoptosis in multiple myeloma cell lines and enhanced expression of proapoptotic genes, including $p 53, p 21, N O X A$ and PUMA [81]. Another orally active proteasome inhibitor, CEP-18770 (delanzomib) shows proteasome-inhibitory activity equivalent to bortezomib, but with better pharmacokinetic properties [82].

\section{Targeting deubiquitinases}

Removal of ubiquitin chains from ubiquitinated proteins is an important regulatory step to counter the outcome of ubiquitination [6]. Like E3 ligases, many deubiquitinases are dysregulated and implicated in various diseases. This is, under many circumstances, dependent on the substrates they deubiquitinate. For example, USP1 deubiquitinates two critical DNA repair proteins, FANCD2 and PCNA, and is therefore involved in Fanconi leukemia $[6,83]$; USP9x deubiquitinates and stabilizes the pro-survival protein MCL1, and a correlation between USP9x expression and MCL1 levels was reported in human follicular lymphomas and diffuse large B-cell lymphomas [84]; USP37 is a deubiquitinase regulating cell cycle by deubiquitinating cyclin $\mathrm{A}$ [85] and c-MYC [86]. Since many of these labile proteins 
stabilized by DUBs are oncoproteins, DUBs represent alternative targets in the ubiquitin system for cancer therapies.

Although potent irreversible inhibitors of DUBs such as ubiquitin aldehyde or ubiquitin vinyl sulfone have been widely used as research tools, currently no DUB inhibitors have entered clinical trials [87]. Among all actively pursued DUB targets, USP7/HAUSP is the most studied due to its critical role in regulating p53 function. For instance, HBX 19,818 was identified to selectively inhibit USP7 by forming a covalent bond with Cys 223 in the active site of USP7 [88]. Another USP7 inhibitor, P5091 selectively inhibits USP7 both in vitro and in vivo [89]. Importantly, the cytotoxicity of P5091 was significantly reduced upon USP7 knockout [89], consistent with its activity being on-target. Furthermore, P5091 induced apoptosis in various multiple myeloma (MM) cell lines as well as patient MM cells, including those resistant to prior treatments such as bortezomib, lenalidomide, and dexamethasone [89]. Despite these positive data, one needs to be cautious since USP7 inhibitors suffer the same caveat as Nutlins: they only stabilize and accumulate wild-type p53, whereas the majority of tumors harbor $\mathrm{p} 53$ mutants.

In most eukaryotes, the removal of ubiquitin chains from target proteins during proteosomal degradation is carried out by proteasome-associated DUBs, including RPH11, UCH37, and USP14 [90]. Since removal of ubiquitin chains is essential for the degradation of target proteins, inhibition of the proteasomal DUBs should have similar outcome as proteasomal inhibitors. Indeed, b-AP15, a purported inhibitor for both $\mathrm{UCH} 37$ and USP14, was able to accumulate ubiquitinated substrates and exhibited excellent efficacy in different in vivo solid tumor models as well as an acute myeloid leukemia model [91]. However, a more selective USP14 inhibitor, IU1, had an opposite effect by enhancing degradation of target proteins, leading to a dose-dependent reduction in overexpressed proteins including Tau [92]. These paradoxical results suggest that selective inhibition of different proteasomal DUBs may have different outcomes; nevertheless they confirm that inhibition of proteasomal DUBs is worthy of attention as a potential cancer therapy.

\section{Enhancing ubiquitination to degrade undruggable targets}

Advances of cancer genomics in the last two decades have significantly deepened our understanding of tumorigenesis; many oncoproteins have been identified and serve as attractive targets for the treatment of cancer. However, the dearth of newly approved drugs in the past decade reflects the challenge faced by the pharmaceutical industry. Many of the identified oncoproteins, especially those bereft of robust enzymatic activity, are deemed uninhibitable, and have thus been dubbed "undruggable", including MYC, $\beta$-catenin, and MCL1 [93]. Interestingly, many of these oncoproteins are subject to ubiquitination-dependent degradation, which is compromised in cancer cells. Therefore, a potentially promising strategy is to recover, or even enhance the ubiquitination and subsequent degradation of these targets to block tumorigenesis. Below we will review some promising strategies to enhance ubiquitination and destabilization of cancer drivers.

\section{"Molecular switches"}

Biological decisions are executed by signaling mechanisms that utilize molecular complexes assembled from cellular constituents (e.g., proteins, oligosaccharides, metabolites, etc.). "Molecular switches" in our context refers to small molecules that are able to bind cellular constituents and induce their assembly into protein complexes with altered activity. They are particularly useful in the ubiquitination cascade since they can modulate relatively weak interactions to produce agonists as well as inhibitors of ubiquitination.

The best example of the concept of a "molecular switch" for ubiquitination is the plant hormone: auxin. Although auxin has been recognized to play a critical role in plant development, its mode of action has only become clear in the last decade. It turns out that auxin binds to an F-box component, TIR1, of the multi-subunit E3 ubiquitin ligase, $\mathrm{SCF}^{\mathrm{TIR} 1}$, and initiates ubiquitination of key transcriptional repressors [94, 95]. Mechanistically, auxin enhances TIR1-substrate affinity by acting as a "molecular glue" (Figure 4A). The mechanism of auxin is not a special case. Another plant hormone, jasmonate, is sensed by the F-box protein CORONATINE INSENSITIVE 1 (COI1) [96].

In mammalian systems, equivalent molecules also play an important role to regulate protein ubiquitination. The RING finger E3 ubiquitin ligase RNF146 (also known as Iduna) is responsible for PARylation-dependent ubiquitination of both AXIN and tankyrases, and positively regulates Wnt signaling [97, 98]. Crystal structure suggests that when iso-ADP-ribose (iso-ADPr), the smallest internal poly (ADP-ribose; PAR) structural unit, binds RNF146 between its WWE and RING domains, it changes the conformation of RNF146 by switching the RING domain from an inactive state to an active one. Without PAR or iso-ADPr, the RING domain is unable to bind E2 conjugating enzymes efficiently [99]. Therefore, PAR or iso-ADPr functions as "molecular switch" to change allosteric conformation of RNF146 and activate 
A

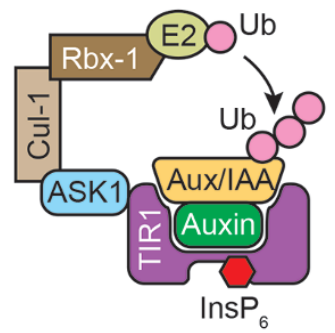

B

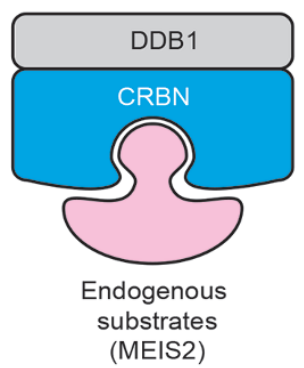

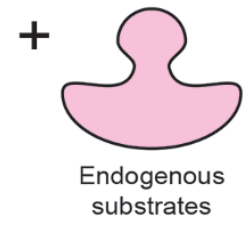

Figure 4 Rationales of enhancing ubiquitination. (A) Auxin is a plant hormone that directly binds to the F-box protein TIR1. With the support of co-factor $\operatorname{InsP}_{6}$, auxin promotes TIR1 interaction with the substrate proteins, AUX/IAAs, leading to enhanced ubiquitination and degradation of substrates. (B) Binding of endogenous substrates to CRBN is blocked by IMiDs molecules, whereas IMiDs recruit neo-substrates (for example: IKZF1 and IKZF3) to CRBN, leading to the stabilization of endogenous substrates but degradation of neo-substrates.

its ligase activity for ubiquitination and degradation of target proteins.

\section{Immunomodulatory drugs}

Originally developed as a sedative, thalidomide was used to treat nausea and morning sickness in pregnant women before its teratogenic effect was revealed. Thalidomide and its derivative molecules (lenalidomide and pomalidomide, together are named immunomodulatory drugs or IMiDs) were later widely used for multiple myeloma patients due to their excellent efficacy, although their mechanism of action had not been clarified until recently $[80,100]$. Taking advantage of high-performance affinity beads for thalidomide, Ito et al. showed that thalidomide binds to Cereblon (CRBN), a critical substrate receptor of the E3 ligase complex CRL4 ${ }^{\text {CRBN }}$ [101]. Surprisingly, later studies suggested that lenalidomide-bound CRBN acquired the ability to target for proteasomal degradation of two essential transcription factors in multiple myeloma: Ikaros family zinc finger proteins 1 and 3 (IKZF1 and IKZF3). Significantly these neo-substrates largely explained lenalidomide's therapeutic effect $[102,103]$.

Although the E3 agonist theory satisfactorily explains the mechanisms of IMiDs in multiple myeloma patients, many outstanding questions remain to be addressed. For example, a decade of clinical trials have revealed that the seemingly antagonistic therapeutic combination of bortezomib (anti-proteolytic) and IMiDs (pro-proteolytic) confers a favorable prognosis compared with either alone $[104,105]$. Furthermore, knockout of CRBN in zebrafish phenocopies the teratogenic effect of thalidomide, suggesting that thalidomide can block the E3 activity of CRL4 ${ }^{\text {CRBN }}$, at least for some substrates [101]. Both of these conundrums can be explained by a model where IMiDs behave as a switch to block ubiquitination of nat- ural substrates of CRL4 ${ }^{\mathrm{CRBN}}$, but promote ubiquitination of neo-substrates, such as IKZF1 and IKZF3 (Figure 4B). Indeed, MEIS2, an endogenous substrate binds CRBN, whereas the neo-substrates IKZF1, 3 are recruited to CRBN through the $\mathrm{C} 4$ amine of lenalidomide or pomalidomide, leading to their ubiquitination [106].

\section{Protein-targeting chimeric molecules}

Like bi-specific antibodies, protein-targeting chimeric molecules (PROTACs) are based on the concept of generating artificial molecules to recruit a specific ubiquitin ligase to a chosen target protein. Therefore, PROTACs behave like bridging molecules that consist of a ligase-recruiting moiety linked through a short linker to a ligand that binds the target protein [107] (Figure 5A). The first proof-of-concept PROTAC, PROTAC-1 was composed of an angiogenesis inhibitor, ovalicin, a covalent binder for the methionine aminopeptidase-2 (MetAP-2), and an I $\mathrm{B}$ phospho-peptide that is recognized by the E3 ligase, $\mathrm{SCF}^{\beta-T R C P}$. In the presence of PROTAC-1, MetAP-2 was recruited to $\mathrm{SCF}^{\beta-T R C P}$, ubiquitinated and degraded in a PROTAC-1-dependent manner [107].

PROTAC technology had remained largely dormant for over a decade due to complex synthetic chemistry, as well as issues of cell permeability. In fact, the first generation of PROTAC was mainly dependent on peptides as the binding moiety for either E3 ligase or target of interest. The development of specific ligands for E3 ligases has significantly improved the technology by providing more drug-like molecules. For example, as the chemical moiety interacting with the E3 enzyme CRBN [106, 108], the phthalimide ring was used as the E3 recruiter, whereas a competitive BET bromodomain inhibitor, JQ1 was used to bind the bromodomain protein BRD4 [109] (Figure 5B), a transcriptional co-activator that reg- 

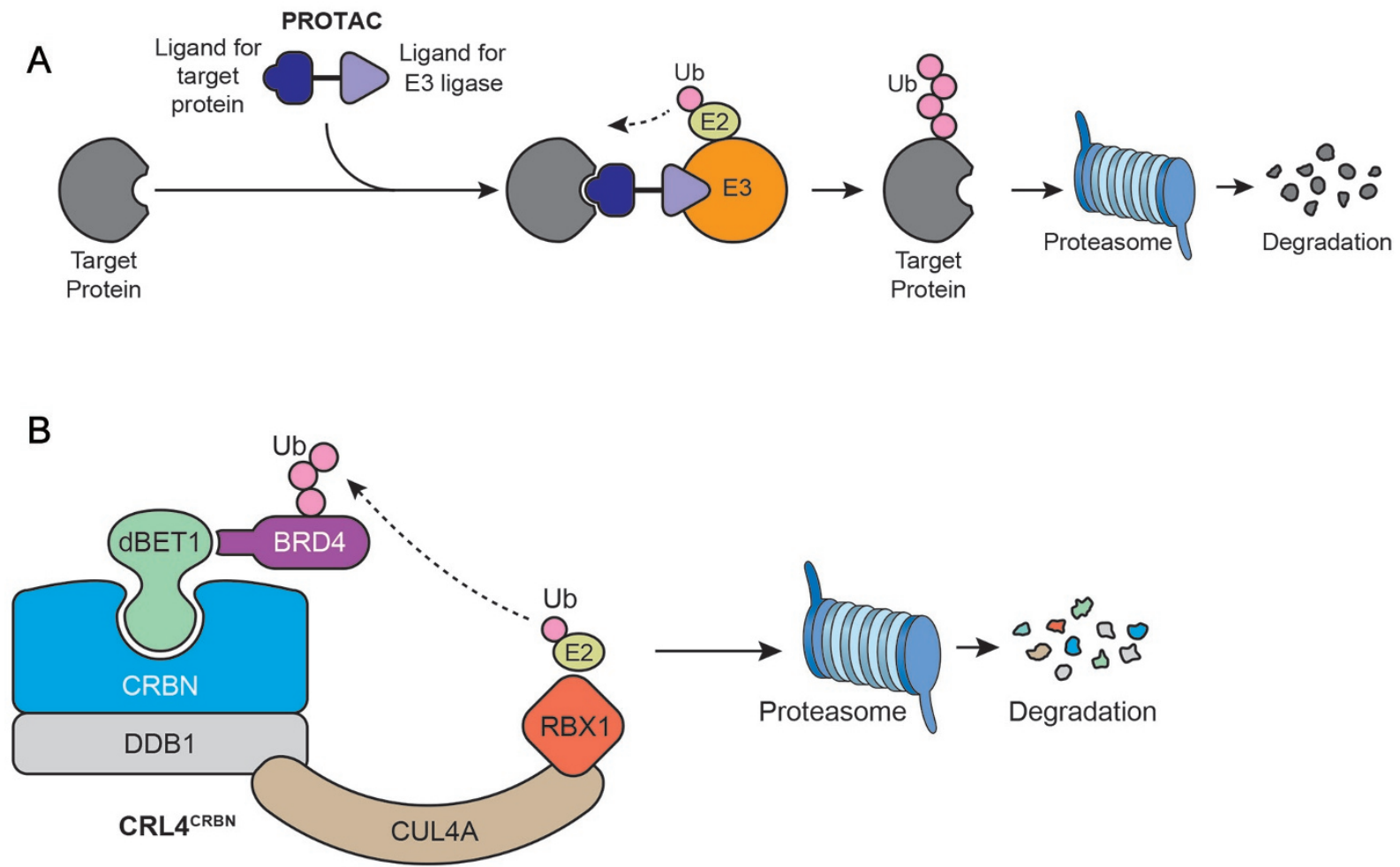

Figure 5 PROTAC as an anti-cancer strategy. (A) PROTACs are bifunctional molecules that are comprised of a targeting ligand tethered to an E3 ligase-recruiting moiety through a short linker. (B) dBET1 as an example of PROTAC. dBET1 is comprised of JQ1 that binds to oncoprotein BRD4, and thalidomide that recruits CRL4 ${ }^{\text {CRBN }}$, an E3 ubiquitin ligase.

ulates the expression of genes that promote cancer cell proliferation and survival [110]. A short linker brings the phthalimide ring together with JQ1 and the hybrid molecule, named dBET1, was confirmed to interact with BRD4 in a mode similar to JQ1. dBET1 treatment induced robust BRD4 degradation, resulting in strong apoptosis in lymphoma cell lines as well as primary blasts from patients with leukemia [111]. Interestingly, dBET1 showed a better efficacy compared with JQ1 in both in vitro and in vivo models, suggesting that target degradation might be preferable to target inhibition [111]. Another PROTAC aiming to remove BRD4, ARV-825 also recruits BRD4 to the CRL4 ${ }^{\mathrm{CRBN}}$, leading to significant degradation of BRD4 in all Burkitt's lymphoma cell lines tested [112]. Similar to dBET1, ARV-825 showed better pharmacodynamics than small-molecule BRD4 inhibitors, with more effective suppression of $c-M Y C$ transcript levels and downstream signaling, resulting in more effective cell proliferation inhibition and apoptosis induction [112].

PROTAC offers an excellent opportunity to degrade many difficult oncoprotein targets. Furthermore, recent discoveries suggest that the earlier bottleneck of PROT-
$\mathrm{AC}$, its relatively low efficacy, is no longer an issue, with reported EC50s in the nanomolar range $[111,112]$. In addition to CRBN, several other PROTACs have been developed employing different E3 enzymes such as CRL2 ${ }^{\mathrm{VHL}}$ [113-115], suggesting that PROTAC could be developed as a platform technology. As a new technology, PROTAC also faces several important challenges. First, as complex large molecules, the major potential drawback is their likely poor oral bioavailability and fickle pharmacokinetic properties. In addition, PROT$\mathrm{AC}$ technology relies on identification of ligands for E3 ligases and oncoproteins, which by itself, could be a daunting task. Furthermore, diagnostics could be a challenge for many PROTAC molecules since target E3 ligases might not necessarily co-express with target proteins in all tissues. Furthermore, most PROTAC molecules may suffer the pharmacological "hook effect", with higher concentrations of PROTACs preventing substrate degradation due to univalent saturation inhibiting bivalent bridging. This would make dosing of PROTACs in patients a tricky challenge. Lastly, a linker is required to connect the two chemical moieties; although both shorter and longer linkers have been reported, it still seems em- 
pirical and optimization is required for each pair of ligase and target protein, since it is likely that optimal linker identity will vary for different proteins targeted.

\section{Hydrophobic tagging}

Correct three-dimensional structure is essential for the function of proteins [116]. A major driving force for protein folding is to minimize the number of hydrophobic side-chains exposed to water [117]. Exposure of hydrophobic residues might cause protein misfolding and engage cellular quality control machinery to induce protein degradation [118] (Figure 6). This machinery could be deployed to remove unwanted oncoproteins by "tagging" them with a synthetic hydrophobic ligand, thereby recruiting quality control machinery to initiate proteasomal degradation.

The concept of "hydrophobic tagging (HyT)" is similar to that of PROTAC, but instead of using a ligand to recruit a specific E3 ligase, a synthetic hydrophobic group, such as adamantane, linked to a chemical moiety that specifically recognizes the protein of interest, assumes the role of "recruiter" for the degradation machinery [119] (Figure 6). Upon binding to the target protein, the hydrophobic tag mimics or induces a misfolded state. Although the precise mechanism of action of HyT is not completely clear, the general consensus is that modification of target proteins with a bulky hydrophobic sidegroup attracts the chaperone machinery, the primary goal of which is to help refold misfolded proteins [120]. Since the covalent modification cannot be easily removed, the target protein remains unfolded and is eventually cleared by ubiquitin-proteasome mediated degradation.

The first proof of concept study was carried out by hydrophobic tagging of the bacterial dehalogenase (HaloTag) with an adamantane moiety. The HyT molecules induced the degradation of HaloTag fusion proteins from different cellular compartments [119]. Using a similar system, ER-localized HaloTag (ERHT) protein was conditionally destabilized using a small hydrophobic tag molecule (HyT36) to reveal the mechanism of ER stress response [121]. Aiming to degrade a pseudo-kinase HER3, Gray and colleagues synthesized a bivalent molecule connecting hydrophobic groups with a non-functional HER3 binder. The resultant HyT molecule TX2-121-1 induced degradation of HER3 and blocked HER3-dependent signaling [122].

An interesting question regarding HyT molecules is whether a covalent ligand for a protein of interest is essential, since most successful HyT molecules are all covalent binders. This could limit the potential of this technology. To this end, a HyT molecule linking the hydrophobic $\mathrm{Boc}_{3} \mathrm{Arg}$ group (a modified arginine amino acid) to trimethoprim (TMP), a non-covalent inhibitor of eDHFR has been generated. The resultant TMP-Boc ${ }_{3} \mathrm{Arg}$ HyT molecule led to $60 \%$ degradation of eDHFR in lysates and $30 \%$ in intact cells, although a high concentration was needed [123], suggesting that non-covalent binders might not be as effective as covalent ones.

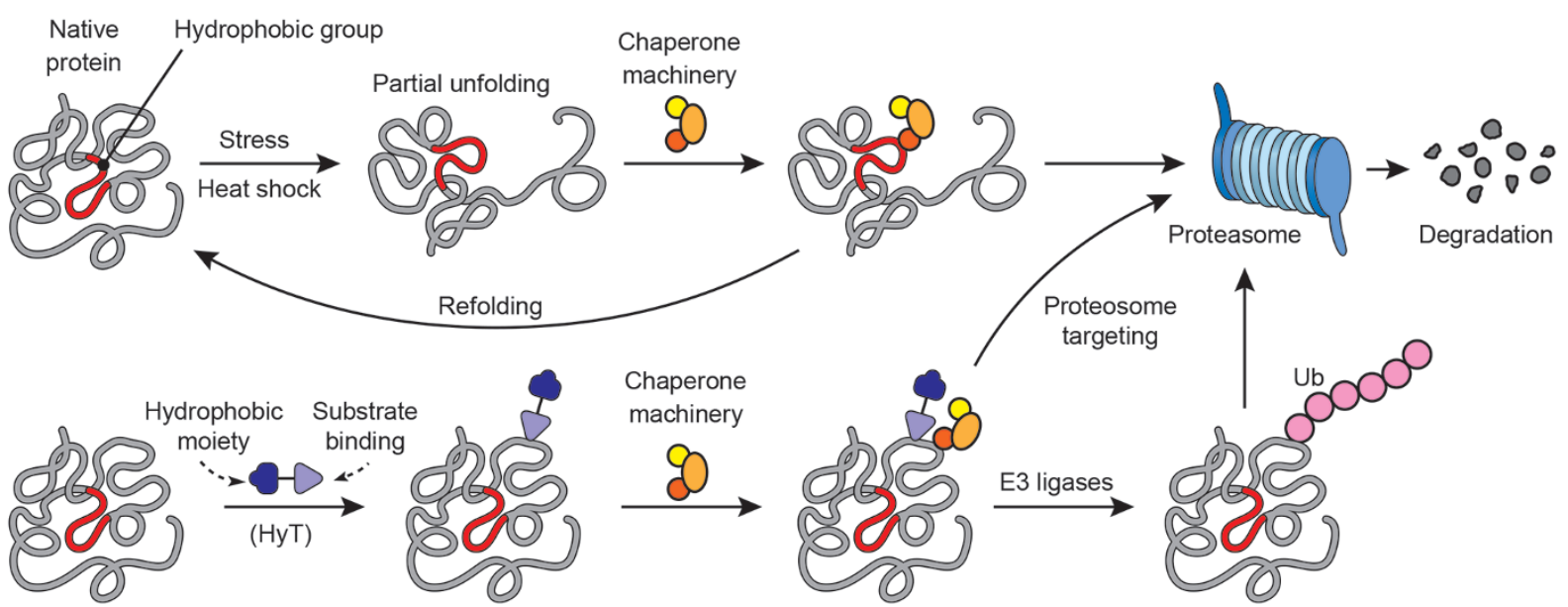

Figure 6 Hydrophobic tagging as an anti-cancer strategy. A partially unfolded protein is assisted by the chaperone machinery to refold back into its native conformation. Proteasome-dependent degradation is triggered if chaperone machinery fails to refold a damaged protein. Hydrophobic tagging molecules are bifunctional molecules comprised of a substrate-recruiting ligand connected with a hydrophobic moiety, such as adamantane. A protein binding to a hydrophobic tagging molecule mimics partially unfolded state to trigger target protein degradation by either directly escorting target to proteasome or initiating ubiquitination of target protein. 
Similar to PROTACs, hydrophobic tagging technology offers great potential to degrade disease-related proteins. The main limiting factor is probably their large size (almost invariably greater than 500 Daltons in mass), and thus likely poor pharmacokinetic properties that may limit their use to systemic administration. Compared with PROTACs, HyT molecules offer one less layer of complexity by avoiding ligands for E3 ligases. It would be interesting to test this platform by appending hydrophobic moieties (such as adamantane) with available ligands for targets of interest, and to test their ability to degrade the target proteins.

\section{Selective estrogen receptor degraders}

Estrogen receptors are a family of nuclear receptors activated by the hormone estrogen [124]. It is estimated that around $70 \%$ of breast cancer patients have over-expressed estrogen receptors. Tamoxifen, and some other ER antagonists in breast tissue, together with aromatase inhibitors, have been widely used for ER-positive breast tumors [124]. But it is almost inevitable that resistance to endocrine therapy eventually arises. Next generation sequencing has revealed that point mutations in ESR1 are drivers for resistance to the existing therapies $[125,126]$. Furthermore, ER antagonists can have agonist properties in certain tissues, like the uterus, complicating their use. Not surprisingly, therefore, there has been considerable interest in developing selective ER downregulators (SERDs) to target ER for degradation [127]. Currently, fulvestrant, an anti-estrogen with pure antagonist activity, is the only SERD molecule approved for the treatment of breast cancer [128]. However, the poor pharmaceutical properties of this injectable drug and its lack of superiority over second line aromatase inhibitors in late stage breast cancer have negatively impacted its clinical use.

Recently, a series of orally bioavailable SERDs were identified and optimized by Genentech/Seragon. The lead compound GDC-0810 showed robust activity in degrading ER- $\alpha$ in MCF-7 cells, and demonstrated anti-cancer activity in both tamoxifen-sensitive and tamoxifen-resistant breast cancer models [129]. Importantly, in phase I/IIa studies that include 41 postmenopausal patients, all of whom had advanced ER-positive breast cancer disease that had progressed after at least 6 months of endocrine therapy, GDC-0810 competed effectively with tracer to occupy the ER at all doses tested, even in patients with ESR1 mutations, suggesting robust target engagement (http://www.aacr.org/Newsroom/pages/ News-Release-Detail.asp $x$ ?ItemID $=711 \#$.VmCWoOOfrRY). Although the mechanism of action by GDC- 0810 is not completely clear at this point, it is suspected that certain E3 enzymes are activated upon ER- $\alpha$ engagement by the GDC compound, leading to its ubiquitination and degradation. Alternatively, SERD molecules might also behave as their SERM (Selective ER Modulators) counterparts, by changing the conformation of the $\alpha 12$ helix of ER, to expose hydrophobic residues that engage the quality control machinery to degrade the ER [130-132].

\section{Conclusions and perspectives}

The success of proteasome inhibitors suggests a great potential to develop more drugs targeting other components of the ubiquitin system. In a conventional view, the ubiquitin activating and proteasomal degradation steps hold most potential since enzymes in each step harbor well-defined activity pockets, although they also suffer from issues of specificity since they can affect hundreds or even thousands proteins that are regulated by the UPS. In contrast, although E3 enzymes lack such pockets and the development of specific inhibitors remains challenging, with advances in bioinformatics and novel technologies including mass spectrometry and high-throughput screening, the development and success of specific E3 inhibitors might soon be within reach. For instance, by using phage display methods, researchers have developed Ub variants that are able to specifically block activities of E3 ligases and DUBs [133]. Further, with help from computer-aided drug design, innovative therapeutic approaches that target protein-protein interactions have risen to the fore, with potential to disrupt interactions of E3 enzymes with their substrates.

The emerging degrader technology offers new vistas to target the "undruggable". With the pre-clinical success of PROTAC, HyT, and SERDs, one can envisage a time when this platform becomes a valuable addition to our pharmaceutical armamentarium allowing the targeting of the most obstreperous oncoproteins. In addition, degrader molecules might be useful to counter the almost inevitable drug resistance that arises from target inhibition. Furthermore, the enhanced degradation of oncoproteins might increase peptide presentation by MHC molecules and thereby synergize with current cancer immunotherapeutics.

\section{Acknowledgments}

We apologize to those whose citations are omitted owing to space limitations. We thank Bruce A and Skelton $\mathrm{N}$ for help with graphics. XH and VMD are employees of Roche/Genentech.

\section{References}

1 Komander D, Rape M. The ubiquitin code. Annu Rev Biochem 2012; 81: 203-229. 
2 Wickliffe KE, Williamson A, Meyer HJ, Kelly A,, Rape M. K11-linked ubiquitin chains as novel regulators of cell division. Trends Cell Biol 2011; 21:656-663.

3 Newton K, Matsumoto ML, Wertz IE, et al. Ubiquitin chain editing revealed by polyubiquitin linkage-specific antibodies. Cell 2008; 134:668-678.

4 Jin L, Williamson A, Banerjee S, Philipp I, Rape M. Mechanism of ubiquitin-chain formation by the human anaphase-promoting complex. 2008; Cell 133:653-665.

5 Walczak H, Iwai K, Dikic I. Generation and physiological roles of linear ubiquitin chains. BMC Biol 2012; 10:23-23.

6 Nijman SM, Luna-Vargas MP, Velds A, et al. A genomic and functional inventory of deubiquitinating enzymes. Cell 2005; 123:773-786.

7 Komander D, Clague MJ, Urbe S. Breaking the chains: structure and function of the deubiquitinases. Nat Rev Mol Cell Biol 2009; 10:550-563.

8 Popovic D, Vucic D, Dikic I. Ubiquitination in disease pathogenesis and treatment. Nat Med 2014; 20:1242-1253.

9 Kitada T, Asakawa S, Hattori N, et al. Mutations in the parkin gene cause autosomal recessive juvenile parkinsonism. $\mathrm{Na}$ ture 1998; 392:605-608.

10 Oliveira AM, Hsi BL, Weremowicz S, et al. USP6 (Tre2) fusion oncogenes in aneurysmal bone cyst. Cancer Res 2004; 64:1920-1923; .

11 Zhang J, Yang PL, Gray NS. Targeting cancer with small molecule kinase inhibitors. Nat Rev Cancer 2009; 9:28-39.

12 Knight ZA, Lin H, Shokat KM. Targeting the cancer kinome through polypharmacology. Nat Rev Cancer 2010; 10:130137.

13 Schulman BA, Wade Harper J. Ubiquitin-like protein activation by E1 enzymes: the apex for downstream signalling pathways. Nat Rev Mol Cell Biol 2009; 10:319-331 .

14 Jin J, Li X, Gygi SP, Harper JW. Dual E1 activation systems for ubiquitin differentially regulate E2 enzyme charging. $\mathrm{Na}$ ture 2007; 447:1135-1138.

15 Yang, Y, Kitagaki J, Dai RM, et al. Inhibitors of ubiquitin-activating enzyme (E1), a new class of potential cancer therapeutics. Cancer Res 2007; 67:9472-9481.

$16 \mathrm{Xu}$ GW, Ali M, Wood TE, et al. The ubiquitin-activating enzyme E1 as a therapeutic target for the treatment of leukemia and multiple myeloma. Blood 2010; 115:2251-2259.

17 Streich FC, Lima CD. Structural and functional insights to ubiquitin-like protein conjugation. Annu Rev Biophys 2014; 43:357-379.

18 Soucy TA, Smith PG, Milhollen MA, et al. An inhibitor of NEDD8-activating enzyme as a new approach to treat cancer. Nature 2009; 458:732-736.

19 Brownell JE, Sintchak MD, Gavin JM, et al. Substrate-assisted inhibition of ubiquitin-like protein-activating enzymes: the NEDD8 E1 inhibitor MLN4924 forms a NEDD8-AMP mimetic in situ. Mol Cell 2010; 37:102-111.

20 Duda DM, Borg LA, Scott DC, Hunt HW, Hammel M, Schulman BA. Structural insights into NEDD8 activation of cullin-RING ligases: conformational control of conjugation. Cell 2008; 134:995-1006.

21 Bennett EJ, Rush J, Gygi SP, Harper JW. Dynamics of cullin-RING ubiquitin ligase network revealed by systematic quantitative proteomics. Cell 2010; 143:951-965.
22 Kim W, Bennett EJ, Huttlin EL, et al. Systematic and quantitative assessment of the ubiquitin-modified proteome. Mol Cell 2011; 44:325-340.

23 Emanuele MJ, Elia AE, Xu Q, et al. Global identification of modular cullin-RING ligase substrates. Cell 2011; 147, 459474.

24 Ye Y, Rape M. Building ubiquitin chains: E2 enzymes at work. Nat Rev Mol Cell Biol 2009; 10:755-764.

25 Ceccarelli DF, Tang X, Pelletier B, et al. An allosteric inhibitor of the human $\mathrm{Cdc} 34$ ubiquitin-conjugating enzyme. Cell 2011; 145:1075-1087.

26 Deng L, Wang C, Spencer E, et al. Activation of the I $\mathrm{B}$ kinase complex by TRAF6 requires a dimeric ubiquitin-conjugating enzyme complex and a unique polyubiquitin chain. Cell 2000; 103:351-361.

27 Pulvino M, Liang Y, Oleksyn D, et al. Inhibition of proliferation and survival of diffuse large B-cell lymphoma cells by a small-molecule inhibitor of the ubiquitin-conjugating enzyme Ubc13-Uev1A. Blood 2012; 120:1668-1677.

28 Pierce JW, Schoenleber R, Jesmok G, et al. Novel inhibitors of cytokine-induced $\mathrm{I} \kappa \mathrm{B} \alpha$ phosphorylation and endothelial cell adhesion molecule expression show anti-inflammatory effects in vivo. J Biol Chem 1997; 272:21096-21103.

29 Strickson S, Campbell DG, Emmerich CH, et al. The anti-inflammatory drug BAY 11-7082 suppresses the MyD88-dependent signalling network by targeting the ubiquitin system. Biochem J 2013; 451:427-437.

30 Li W, Bengtson MH, Ulbrich A, et al. Genome-wide and functional annotation of human E3 ubiquitin ligases identifies MULAN, a mitochondrial E3 that regulates the organelle's dynamics and signaling. PLoS One 2008; 3:e1487.

31 Berndsen CE, Wolberger C. New insights into ubiquitin E3 ligase mechanism. Nat Struct Mol Biol 2014; 21:301-307.

32 Deshaies RJ, Joazeiro CA. RING domain E3 ubiquitin ligases. Ann Rev Biochem 2009; 78:399-434.

33 Spratt Donald E, Walden H, Shaw GS. RBR E3 ubiquitin ligases: new structures, new insights, new questions. Biochem $J$ 2014; 458:421-437.

34 Wang Z, Liu P, Inuzuka H, Wei W. Roles of F-box proteins in cancer. Nat Rev Cancer 2014; 14:233-247.

35 Carrano AC, Eytan E, Hershko A, Pagano M. SKP2 is required for ubiquitin-mediated degradation of the CDK inhibitor p27. Nat Cell Biol 1999; 1:193-199.

36 Sutterluty H, Chatelain E, Marti A, et al. p45SKP2 promotes p27Kip1 degradation and induces $\mathrm{S}$ phase in quiescent cells. Nat Cell Biol 1999; 1:207-214.

37 Yu ZK, Gervais JL, Zhang H. Human CUL-1 associates with the SKP1/SKP2 complex and regulates p21(CIP1/WAF1) and cyclin D proteins. Proc Natl Acad Sci USA 1998; 95:1132411329.

38 Chan CH, Li CF, Yang WL, et al. The Skp2-SCF E3 ligase regulates Akt ubiquitination, glycolysis, herceptin sensitivity, and tumorigenesis. Cell 2012; 149:1098-1111.

39 Radke S, Pirkmaier A, Germain D. Differential expression of the F-box proteins Skp2 and Skp2B in breast cancer. Oncogene 2005; 24:3448-3458 .

40 Li J-Q, Wu F, Masaki T, et al. Correlation of Skp2 with carcinogenesis, invasion, metastasis, and prognosis in colorectal tumors. Int J Oncol 2004; 25:87-95 . 
41 Seki R, Ohshima K, Fujisaki T, et al. Prognostic significance of S-phase kinase-associated protein 2 and p27kip1 in patients with diffuse large B-cell lymphoma: effects of rituximab. Ann Oncol 2010; 21:833-841.

42 Gstaiger M, Jordan R, Lim M, et al. Skp2 is oncogenic and overexpressed in human cancers. Proc Natl Acad Sci USA 2001; 98:5043-5048.

$43 \mathrm{Lu} \mathrm{M}$, Ma J, Xue W, et al. The expression and prognosis of FOXO3a and Skp2 in human hepatocellular carcinoma. Pathol Oncol Res 2009; 15:679-687.

44 Souers AJ, Leverson JD, Boghaert ER, et al. ABT-199, a potent and selective BCL-2 inhibitor, achieves antitumor activity while sparing platelets. Nat Med 2013; 19:202-208.

45 Wu L, Grigoryan AV, Li Y, Hao B, Pagano M, Cardozo TJ. Specific small molecule inhibitors of Skp2-mediated p27 degradation. Chem Biol 2012; 19:1515-1524.

46 Chan $\mathrm{CH}$, Morrow JK, Li CF, et al. Pharmacological inactivation of Skp2 SCF ubiquitin ligase restricts cancer stem cell traits and cancer progression. Cell 2013; 154:556-568.

47 Zheng N, Schulman BA, Song L, et al. Structure of the Cul1Rbx1-Skp1-F boxSkp2 SCF ubiquitin ligase complex. Nature 2002; 416:703-709.

48 Levine AJ. p53, the cellular gatekeeper for growth and division. Cell 1997; 88:323-331.

49 Momand J, Zambetti GP, Olson DC, George D, Levine AJ. The $m d m-2$ oncogene product forms a complex with the p53 protein and inhibits p53-mediated transactivation. Cell 1992; 69:1237-1245.

50 Kussie PH, Gorina S, Marechal V, et al. Structure of the MDM2 oncoprotein bound to the p53 tumor suppressor transactivation domain. Science 1996; 274:948-953.

51 Haupt Y, Maya R, Kazaz A, Oren M. Mdm2 promotes the rapid degradation of p53. Nature 1997; 387:296-299.

52 Ladanyi M, Cha C, Lewis R, Jhanwar SC, Huvos AG, Healey JH. MDM2 gene amplification in metastatic osteosarcoma. Cancer Res 1993; 53:16-18.

53 Quesnel B, Preudhomme C, Oscier D, et al. Over-expression of the MDM2 gene is found in some cases of haematological malignancies. Br J Haematol 1994; 88:415-418.

54 McCann AH, Kirley A, Carney DN, et al. Amplification of the $M D M 2$ gene in human breast cancer and its association with MDM2 and p53 protein status. Br J Cancer 1995; 71:981985.

55 Vassilev LT, Vu BT, Graves B, et al. In vivo activation of the p53 pathway by small-molecule antagonists of MDM2. Science 2004; 303:844-848.

56 Shangary S, Qin D, McEachern D, et al. Temporal activation of p53 by a specific MDM2 inhibitor is selectively toxic to tumors and leads to complete tumor growth inhibition. Proc Natl Acad Sci USA 2008; 105:3933-3938.

57 Issaeva N, Bozko P, Enge M, et al. Small molecule RITA binds to p53, blocks p53-HDM-2 interaction and activates p53 function in tumors. Nat Med 2004; 10:1321-1328.

58 Lukashchuk N, Vousden KH. Ubiquitination and degradation of mutant p53. Mol Cell Biol 2007; 27:8284-8295.

59 Lambert JM, Gorzov P, Veprintsev DB, et al. PRIMA-1 reactivates mutant $\mathrm{p} 53$ by covalent binding to the core domain. Cancer Cell 2009; 15:376-388.

60 Deveraux QL, Reed JC. IAP family proteins-suppressors of apoptosis. Genes Dev 1999; 13:239-252 .

61 Vaux DL, Silke J. IAPs, RINGs and ubiquitylation. Nat Rev Mol Cell Biol 2005; 6:287-297.

62 Silke J, Vucic D. IAP family of cell death and signaling regulators. In: Ashkenazi A, Wells JA, Yuan JY, eds. Methods in Enzymology Vol 545. Academic Press, 2014: 35-65.

63 Fulda S, Vucic D. Targeting IAP proteins for therapeutic intervention in cancer. Nat Rev Drug Discov 2012; 11:109-124.

64 Du C, Fang M, Li Y, Li L, Wang X. Smac, a mitochondrial protein that promotes cytochrome c-dependent caspase activation by eliminating IAP inhibition. Cell 2000; 102:33-42.

65 Verhagen AM, Ekert PG, Pakusch M, et al. Identification of DIABLO, a mammalian protein that promotes apoptosis by binding to and antagonizing IAP proteins. Cell 2000; 102:4353.

66 Varfolomeev E, Blankenship JW, Wayson SM, et al. IAP antagonists induce autoubiquitination of c-IAPs, NF-kappaB activation, and TNFalpha-dependent apoptosis. Cell 2007; 131:669-681.

67 Dueber EC, Schoeffler AJ, Lingel A, et al. Antagonists induce a conformational change in cIAP1 that promotes autoubiquitination. Science 2011; 334:376-380 .

68 Hasselgren PO, Wray C, Mammen J. Molecular regulation of muscle cachexia: it may be more than the proteasome. Biochem Biophys Res Commun 2002; 290:1-10.

69 Tisdale MJ. Cachexia in cancer patients. Nat Rev Cancer 2002; 2:862-871

70 Adams J. The development of proteasome inhibitors as anticancer drugs. Cancer Cell 2004; 5:417-421.

71 Hideshima T, Richardson P, Chauhan D, et al. The proteasome inhibitor PS-341 inhibits growth, induces apoptosis, and overcomes drug resistance in human multiple myeloma cells. Cancer Res 2001; 61:3071-3076.

72 Chauhan D, Hideshima T, Mitsiades C, Richardson P, Anderson KC. Proteasome inhibitor therapy in multiple myeloma. Mol Cancer Ther 2005; 4:686-692 .

73 Hideshima T, Richardson P, Chauhan D, et al. Molecular mechanisms mediating antimyeloma activity of proteasome inhibitor PS-341. Blood 2002; 101:1530-1534.

74 Liu FT, Agrawal SG, Gribben JG, et al. Bortezomib blocks Bax degradation in malignant $\mathrm{B}$ cells during treatment with TRAIL. Blood 2007; 111:2797-2805 .

75 Pei XY, Dai Y, Grant S. Synergistic induction of oxidative injury and apoptosis in human multiple myeloma cells by the proteasome inhibitor bortezomib and histone deacetylase inhibitors. Clin Cancer Res 2004; 10:3839-3852 .

76 Kortuem KM, Stewart AK. Carfilzomib. Blood 2013; 121:893-897.

77 Meng L, Mohan R, Kwok BH, Elofsson M, Sin N, Crews $\mathrm{CM}$. Epoxomicin, a potent and selective proteasome inhibitor, exhibits in vivo antiinflammatory activity. Proc Natl Acad Sci USA 1999; 96:10403-10408 .

78 Demo SD, Kirk CJ, Aujay MA, et al. Antitumor activity of PR-171, a novel irreversible inhibitor of the proteasome. Cancer Res 2007; 67:6383-6391 .

79 Groll M, Kim KB, Kairies N, Huber R, Crews CM. Crystal structure of epoxomicin:20S proteasome reveals a molecular

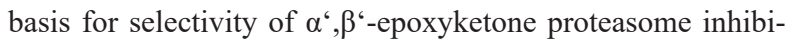
tors. J Am Chem Soc 2000; 122:1237-1238. 
80 Dimopoulos MA, Richardson PG, Moreau P, Anderson KC. Current treatment landscape for relapsed and/or refractory multiple myeloma. Nat Rev Clin Oncol 2015; 12:42-54.

81 Chauhan D, Tian Z, Zhou B, et al. In vitro and in vivo selective antitumor activity of a novel orally ioavailable proteasome inhibitor MLN9708 against multiple myeloma cells. Clin Cancer Res 2011; 17:5311-5321.

82 Seavey MM, Lu LD, Stump KL, Wallace NH, Ruggeri BA. Novel, orally active, proteasome inhibitor, delanzomib (CEP18770, ameliorates disease symptoms and glomerulonephritis in two preclinical mouse models of SLE. Int Immunopharmacol 2012; 12:257-270.

83 Kim JM, Parmar K, Huang M, et al. Inactivation of murine Usp1 results in genomic instability and a fanconi anemia phenotype. Dev Cell 2009; 16:314-320.

84 Schwickart M, Huang X, Lill JR, et al. Deubiquitinase USP9X stabilizes MCL1 and promotes tumour cell survival. $\mathrm{Na}$ ture 2010; 463:103-107.

85 Huang X, Summers MK, Pham V, et al. Deubiquitinase USP37 is activated by CDK2 to antagonize APC(CDH1) and promote S phase entry. Mol Cell 2011; 42:511-523.

86 Pan J, Deng Q, Jiang C, et al. USP37 directly deubiquitinates and stabilizes c-Myc in lung cancer. Oncogene 2015; 34:3957-3967.

87 Lill JR, Wertz IE. Toward understanding ubiquitin-modifying enzymes: from pharmacological targeting to proteomics. Trends Pharmacol Sci 2014; 35:187-207.

88 Reverdy C, Conrath S, Lopez R, et al. Discovery of specific inhibitors of human USP7/HAUSP deubiquitinating enzyme. Chem Biol 2012; 19:467-477.

89 Chauhan D, Tian Z, Nicholson B, et al. A small molecule inhibitor of ubiquitin-specific protease-7 induces apoptosis in multiple myeloma cells and overcomes bortezomib resistance. Cancer Cell 2012; 22:345-358.

90 Bhattacharyya S, Yu H, Mim C, Matouschek A. Regulated protein turnover: snapshots of the proteasome in action. Nat Rev Mol Cell Biol 2014; 15:122-133.

91 D'Arcy P, Brnjic S, Olofsson MH, et al. Inhibition of proteasome deubiquitinating activity as a new cancer therapy. Nat Med 2011; 17:1636-1640.

92 Lee BH, Lee MJ, Park S, et al. Enhancement of proteasome activity by a small-molecule inhibitor of USP14. Nature 2010; 467:179-184.

93 Nero TL, Morton CJ, Holien JK, Wielens J, Parker MW. Oncogenic protein interfaces: small molecules, big challenges. Nat Rev Cancer 2014; 14:248-262.

94 Gray WM, Kepinski S, Rouse D, Leyser O, Estelle M. Auxin regulates SCFTIR1-dependent degradation of AUX/IAA proteins. Nature 2001; 414:271-276.

95 Ruegger M, Dewey E, Gray WM, Hobbie L, Turner J, Estelle $\mathrm{M}$ et al. The TIR1 protein of Arabidopsis functions in auxin response and is related to human SKP2 and yeast Grr1p. Genes Dev 1998; 12:198-207.

96 Sheard LB, Tan X, Mao H, et al. Jasmonate perception by inositol-phosphate-potentiated COI1-JAZ co-receptor. Nature 2010; 468:400-405.

97 Zhang Y, Liu S, Mickanin C, et al. RNF146 is a poly(ADP-ribose)-directed E3 ligase that regulates axin degradation and Wnt signalling. Nat Cell Biol 2011; 13:623-629.
98 Callow MG, Tran H, Phu L, et al. Ubiquitin ligase RNF146 regulates tankyrase and axin to promote Wnt signaling. PLoS One 2011; 6:e22595.

99 DaRosa PA, Wang Z2, Jiang X, et al. Allosteric activation of the RNF146 ubiquitin ligase by a poly(ADP-ribosyl)ation signal. Nature 2015; 517:223-226.

100 Yang B, Yu RL, Chi XH, Lu XC. Lenalidomide treatment for multiple myeloma: systematic review and meta-analysis of randomized controlled trials. PLoS One 2013; 8:e64354.

101 Ito T, Ando H, Suzuki T, et al. Identification of a primary target of thalidomide teratogenicity. Science 2010; 327:13451350 .

102 Lu G, Middleton RE, Sun H, et al. The myeloma drug lenalidomide promotes the cereblon-dependent destruction of Ikaros proteins. Science 2014; 343:305-309.

103 Kronke J, Udeshi ND, Narla A, et al. Lenalidomide causes selective degradation of IKZF1 and IKZF3 in multiple myeloma cells. Science 2014; 343:301-305.

104 Richardson PG, Xie W, Jagannath S, et al. A phase 2 trial of lenalidomide, bortezomib, and dexamethasone in patients with relapsed and relapsed/refractory myeloma. Blood 2014; 123:1461-1469.

105 Richardson PG, Weller E, Jagannath S, et al. Multicenter, phase I, dose-escalation trial of lenalidomide plus bortezomib for relapsed and relapsed/refractory multiple myeloma. J Clin Oncol 2009; 27:5713-5719.

106 Fischer ES, Böhm K, Lydeard JR, et al. Structure of the DDB1-CRBN E3 ubiquitin ligase in complex with thalidomide. Nature 2014; 512:49-53.

107 Sakamoto KM, Kim KB, Kumagai A, Mercurio F, Crews CM, Deshaies RJ. PROTACs: chimeric molecules that target proteins to the Skp1-Cullin-F box complex for ubiquitination and degradation. Proc Natl Acad Sci USA 2001; 98:8554-8559.

108 Chamberlain PP, Lopez-Girona A, Miller K, et al. Structure of the human Cereblon-DDB1-lenalidomide complex reveals basis for responsiveness to thalidomide analogs. Nat Struct Mol Biol 2014; 21:803-809.

109 Filippakopoulos P, Qi J, Picaud S, et al. Selective inhibition of BET bromodomains. Nature 2010; 468:1067-1073.

110 Delmore JE, Issa GC, Lemieux ME, et al. BET bromodomain inhibition as a therapeutic strategy to target c-Myc. Cell 2011; 146:904-917.

111 Winter GE, Buckley DL, Paulk J, et al. Phthalimide conjugation as a strategy for in vivo target protein degradation. Science 2015; 348:1376-1381.

$112 \mathrm{Lu} \mathrm{J}$, Qian Y, Altieri M, et al. Hijacking the E3 ubiquitin ligase cereblon to efficiently target BRD4. Chem Biol 2015; 22:755-763.

113 Buckley DL, Raina K, Darricarrere N, et al. HaloPROTACS: use of small molecule PROTACs to induce degradation of HaloTag fusion proteins. ACS Chem Biol 2015; 10:18311837.

114 Zengerle M, Chan KH, Ciulli A. Selective small molecule induced degradation of the BET bromodomain protein BRD4. ACS Chem Biol 2015; 10:1770-1777.

115 Bondeson DP, Mares A, Smith IE, et al. Catalytic in vivo protein knockdown by small-molecule PROTACs. Nat Chem Biol 2015; 11:611-617.

116 Anfinsen CB. Principles that govern the folding of protein 
chains. Science 1973; 181:223-230.

117 Pace CN, Shirley BA, McNutt M, Gajiwala K. Forces contributing to the conformational stability of proteins. FASEB $J$ 1996; 10:75-83.

118 Lins L, Brasseur R. The hydrophobic effect in protein folding. FASEB J 1995; 9:535-540.

119 Neklesa TK, Tae HS, Schneekloth AR, et al. Small-molecule hydrophobic tagging-induced degradation of HaloTag fusion proteins. Nat Chem Biol 2011; 7:538-543.

120 McClellan AJ, Tam S, Kaganovich D, Frydman J. Protein quality control: chaperones culling corrupt conformations. Nat Cell Biol 2005; 7:736-741.

121 Raina K, Noblin DJ, Serebrenik YV, et al. Targeted protein destabilization reveals an estrogen-mediated ER stress response. Nat Chem Biol 2014; 10:957-962.

122 Xie T, Lim SM, Westover KD, et al. Pharmacological targeting of the pseudokinase Her3. Nat Chem Biol 2014; 10:10061012.

123 Long MJ, Gollapalli DR, Hedstrom L. Inhibitor mediated protein degradation. Chem Biol 2012; 19:629-637.

124 Jensen EV, Jordan VC. The estrogen receptor: a model for molecular medicine. Clin Cancer Res 2003; 9:1980-1989 .

125 Toy W, Shen Y, Won H, et al. ESR1 ligand-binding domain mutations in hormone-resistant breast cancer. Nat Genet 2013; 45:1439-1445.

126 Robinson DR, Wu YM, Vats P, et al. Activating ESR1 mutations in hormone-resistant metastatic breast cancer. Nat Genet 2013; 45:1446-1451.

127 Nawaz Z, Lonard DM, Dennis AP, Smith CL, O’Malley BW. Proteasome-dependent degradation of the human estrogen re- ceptor. Proc Natl Acad Sci USA 1999; 96:1858-1862.

128 Wakeling AE, Dukes M, Bowler J. A potent specific pure antiestrogen with clinical potential. Cancer Res 1991; 51:38673873.

129 Lai A, Kahraman M, Govek S, et al. Identification of GDC0810 (ARN-810), an orally bioavailable selective estrogen receptor degrader (SERD) that demonstrates robust activity in tamoxifen-resistant breast cancer xenografts. $J$ Med Chem 2015; 58:4888-4904.

130 Shiau AK, Barstad D, Loria PM, et al. The structural basis of estrogen receptor/coactivator recognition and the antagonism of this interaction by tamoxifen. Cell 1998; 95:927-937.

131 Shiau AK, Barstad D, Radek JT, et al. Structural characterization of a subtype-selective ligand reveals a novel mode of estrogen receptor antagonism. Nat Struct Mol Biol 2002; 9:359364 .

$132 \mathrm{Wu}$ YL, Yang X, Ren Z, et al. Structural basis for an unexpected mode of SERM-mediated ER antagonism. Mol Cell 2005; 18:413-424.

133 Ernst A, Avvakumov G, Tong J, et al. A strategy for modulation of enzymes in the ubiquitin system. Science 2013; 339:590-595.

(c) (i) () $\odot$ This work is licensed under a Creative Commons Attribution-NonCommercial-NoDerivs 4.0 Unported License. The images or other third party material in this article are included in the article's Creative Commons license, unless indicated otherwise in the credit line; if the material is not included under the Creative Commons license, users will need to obtain permission from the license holder to reproduce the material. To view a copy of this license, visit http://creativecommons.org/licenses/by-nc-nd/4.0/ 